\title{
Real-Time Monitoring of Currents and Water Level at Second Narrows to Improve Port Efficiency in Vancouver Harbour
}

\author{
D. D. Lemon, R. A. J. Chave \\ and M. R. Clarke \\ ASL Environmental Sciences Inc \\ 1986 Mills Rd \\ Sidney, BC V8L 5 Y3 Canada \\ asl@aslenv.com
}

\author{
T. A. Curran, W. Hinds, A. \\ Thorn and A. Thomson \\ Canadian Hydrographic Service \\ PO Box 6000 \\ 9860 West Saanich Rd. \\ Sidney, BC V8L 4B2 Canada
}

\author{
Capt. C. J. Badger \\ Vancouver Port Authority \\ 1900-200 Granville Street \\ Vancouver BC V6C 2P9 \\ Canada
}

\begin{abstract}
A real-time monitoring system for currents and water levels was installed at Second Narrows in the Port of Vancouver in March 2001. Second Narrows restricts the movement of marine traffic into the upper harbour because of its strong tidal streams, limited depth and the presence of both a vehicular bridge and a rail bridge. The Port of Vancouver undertook a joint project with the Canadian Hydrographic Service (CHS), CN Rail and terminal operators in the upper harbour to replace the present system of predicted water levels and currents with an on-site measurement system at the rail bridge. Water levels and currents are measured at the Narrows; bridge and draft clearances are calculated and the results telemetered to the Port management and traffic control centre for real-time display.
\end{abstract}

Current data are provided by an Acoustic Scintillation Flow Meter (ASFM), manufactured by ASL Environmental Sciences Inc. of Sidney, BC. Water level data are provided by an Aquatrak sensor manufactured by Bartex of Annapolis, MD. Currents are measured at two depths, and water level at one point under the bridge, every 5 minutes. The display shows a 24-hour history of currents at both levels, and the measured water level (the full data history is also stored). The current data show significant departures from the predicted tidal flows as, to a lesser extent, do the water level data.

The system has operated in a trial mode for the past two years to assess its operational reliability. During this period two significant outages occurred. Modifications to the installation and to maintenance procedures to prevent their recurrence are described, and future plans for the operational use of the system are discussed.

\section{INTRODUCTION}

Vancouver is Canada's chief west coast port and as such handles a large and increasing volume of marine traffic every year. The harbour consists of two main basins, separated by a narrow channel, called Second Narrows (Fig. 1). Second Narrows restricts the movement of traffic into the upper harbour because of its strong tidal streams, limited depth and the presence of both a highway and rail bridge (Fig. 2). The rail bridge has a lift span, which must be raised to allow deep-sea vessels to pass into the upper harbour, interrupting rail traffic across the bridge.

The passage beneath the lift span is 160 metres wide, and has peak tidal streams of $3 \mathrm{~m} / \mathrm{s}$. The mid-channel depth at lowest normal tide is $14 \mathrm{~m}$. The passage of large

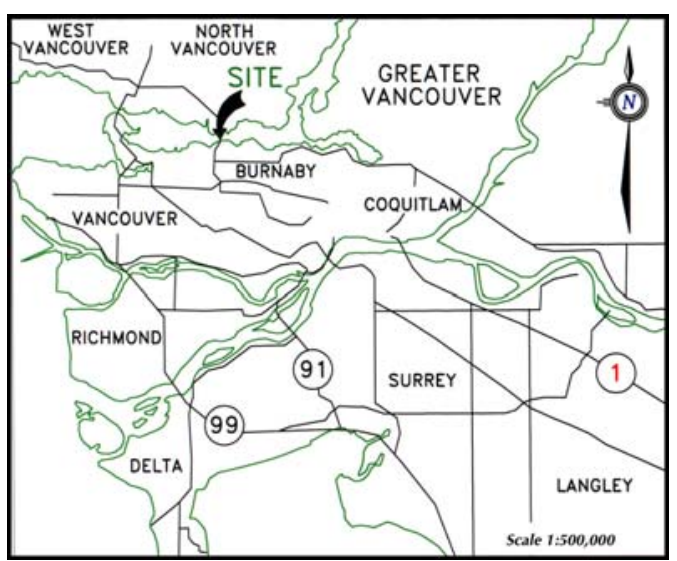

Fig. 1 Vancouver Harbour

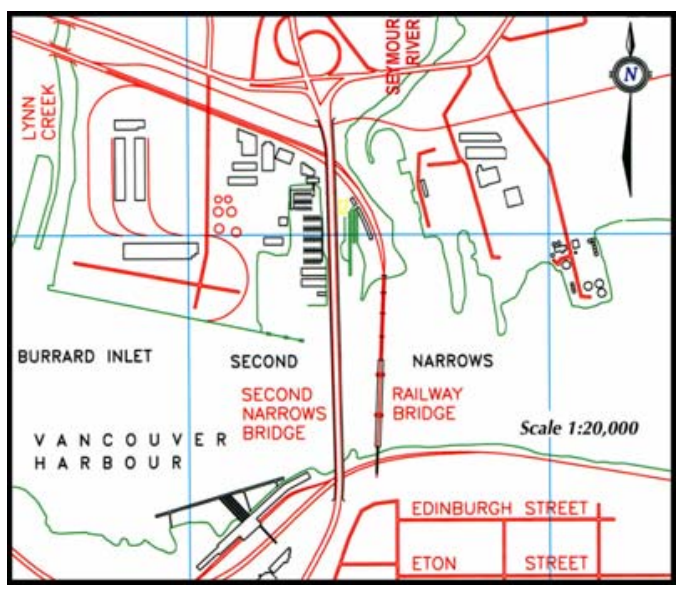

Fig. 2 Second Narrows

ships through the channel is therefore restricted to periods when the depth is sufficiently great and the current speed sufficiently low to allow safe manoeuvring. A collision in the early 1970s, which caused significant damage to the bridge, led to tighter restrictions on permissible limits for vessel passage. The times of passage are calculated from the Canadian Hydrographic Service (CHS) tide and current tables for Second Narrows, derived from measurements taken in the mid 1960s. Since the actual current and water level deviates from the predictions due to a variety of causes (weather and runoff conditions, etc.) the conditions 
for passage are set conservatively. Real-time measurement of the currents and water levels at the Narrows therefore offers the possibility of increasing the permitted times of passage, and of modifying the predictions as actual conditions are influenced by non-tidal forces.

The Port of Vancouver undertook a joint project with CHS, CN Rail and terminal operators in the upper harbour to install an on-site, real-time measurement system at the rail bridge. The system measures the water level and currents at the Narrows, and telemeters the results to the Port management and traffic control centre for real-time display. Bridge and draft clearances are calculated and displayed as well.

\section{INSTRUMENTATION}

An Acoustic Scintillation Flow Meter (ASFM) was chosen to measure the currents at the Narrows. The water level is measured by an Aquatrak sensor manufactured by Bartex of Annapolis, MD.

\section{A. Acoustic Scintillation Flow Meter}

The ASFM was selected for the current measurement because it requires no cabling or sensors in the shipping channel. This was an important consideration given the high current speeds, shallow depth and heavy traffic in Second Narrows. The ASFM uses a method called acoustic scintillation drift to measure the current in the channel. This method exploits the effects of the turbulence in the flowing water on sound signals propagated across the channel to measure the speed of the current. It has previously been used to measure currents in ocean channels [1-3] and rivers [4].

Fig. 3 shows a schematic representation of an ASFM in use. Two transmitters are placed at one side of the channel, two receivers at the other. The signal amplitude at the receivers varies randomly in time as the distribution of turbulence along the propagation paths changes with time and the flow. If the paths are sufficiently closely-spaced,

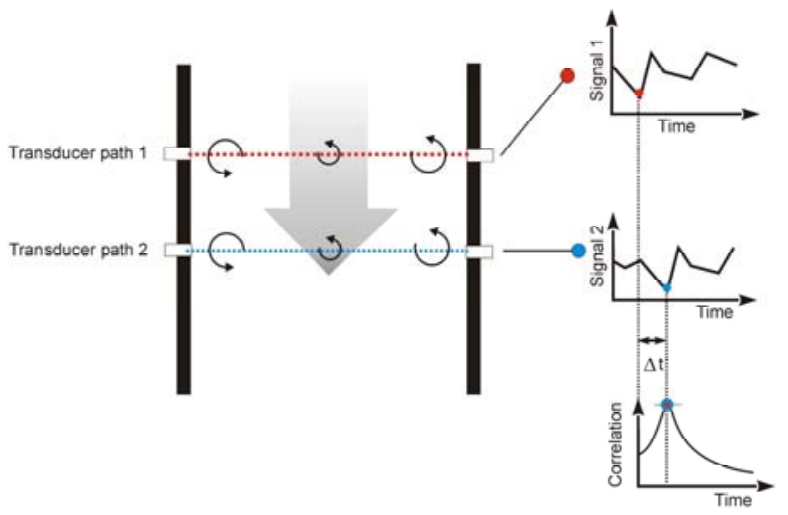

Fig. 3 Schematic representation of current measurement by acoustic scintillation the turbulence may be regarded as being embedded in the mean flow, and then the pattern of these variations (known as scintillations) at the downstream receiver will be nearly identical to that at the upstream receiver, except for a time delay, $\Delta t$. The mean flow velocity perpendicular to the acoustic beams is $\Delta x / \Delta t$, where $\Delta x$ is the separation between the beams [2].

\section{B. Water Level Measurements}

The Bartex Aquatrak sensor uses acoustic signals sent through the air to measure the position of the water surface inside a stilling well. The transducer is mounted at the top of the stilling well at the end of a copper tube. Acoustic pulses sent down the tube reflect from the water surface; the arrival time of the echo is used to compute the distance to the surface. A reference target, mounted at a known position in the tube, is used to compensate for changes in the speed of sound.

\section{INSTALLATION}

The piers of the railway bridge at Second Narrows provide a nearly ideal location for a scintillation flow meter. The main shipping channel runs between the piers, below the lift span (Fig. 4). Fig. 5 shows a schematic diagram of the layout of the system components on the bridge. The current is measured at two levels, and the water level at one location at the south pier. The acoustic transducers are mounted on carriages that can be raised and lowered on tracks for servicing and to allow the measurement depth to be altered if required. The ASFM receiving transducers and the water level sensor are located on the south pier and connected (via a cable run in conduit) to the receiver and signal processor in the bridge operation room in the south tower. The ASFM transmitter operates as an independent unit; the electronics are mounted in a weatherproof case on the north pier. Power is supplied from the mains via an uninterruptible power supply and filter. The primary data transmission link is by Ethernet from the bridge by broadband radio link to a fibre optic

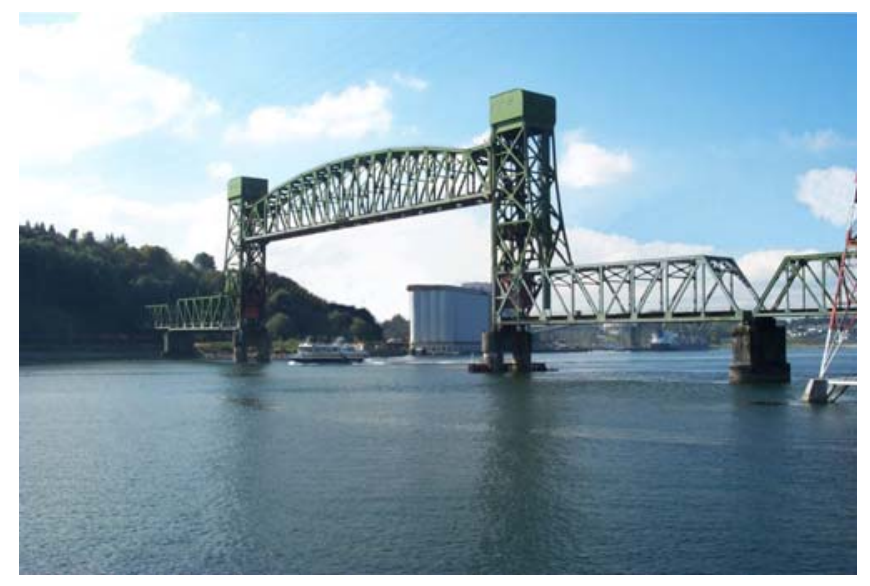

Fig. 4 Second Narrows rail bridge 


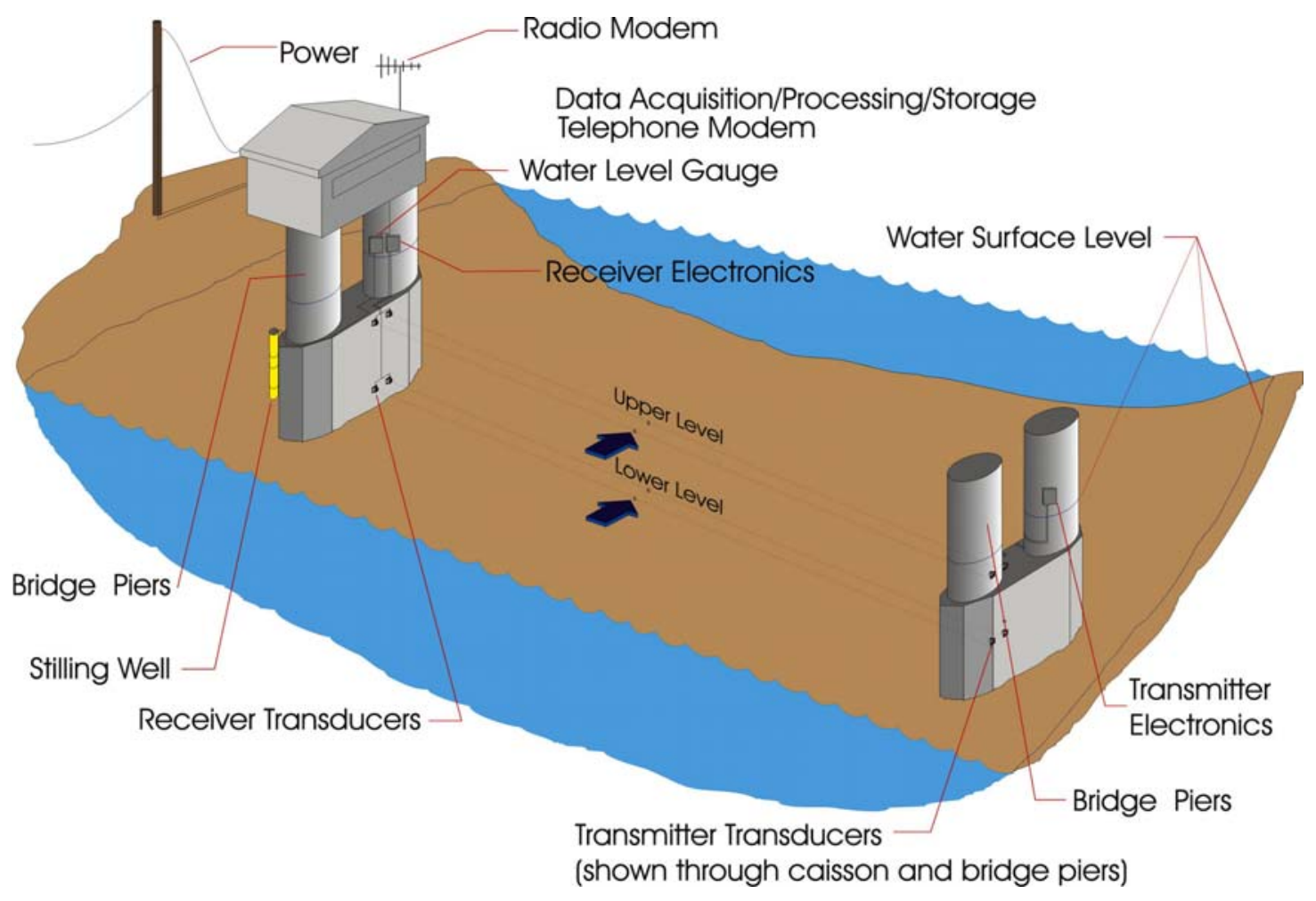

Fig. 5 Schematic layout of the system components

cable $5 \mathrm{~km}$ away, which is directly connected to the VPA offices. A dial-up modem connection provides backup and limited capacity to control the system operation remotely.

Figure 6 shows a photo of part of the supporting tracks and a transducer array carriage. The tracks themselves are square cross-section pipes, set at an angle to allow the carriage wheels to run along them. The carriages are attached to an endless cable loop and counterweights, to allow them to be raised and lowered easily. Each array carries two transducers, separated horizontally by $14 \mathrm{~cm}$. The arrays were set at depths of 4.3 and 8.3 metres (at lowest normal tide). The deeper path was included to provide data near the depth of large draft ships, and to avoid the signal interruption and degradation on the upper level caused by vessels passing through the Narrows and their wakes.

\section{OPERATION}

\section{A. Data Collection}

The system produces a value of the current at each depth and the water level every 5 minutes. The ASFM transmits pulses of $300 \mathrm{kHz}$ sound $27 \mu \mathrm{sec}$ long at $40 \mathrm{~Hz}$ from each projector. Time-division multiplexing is used to

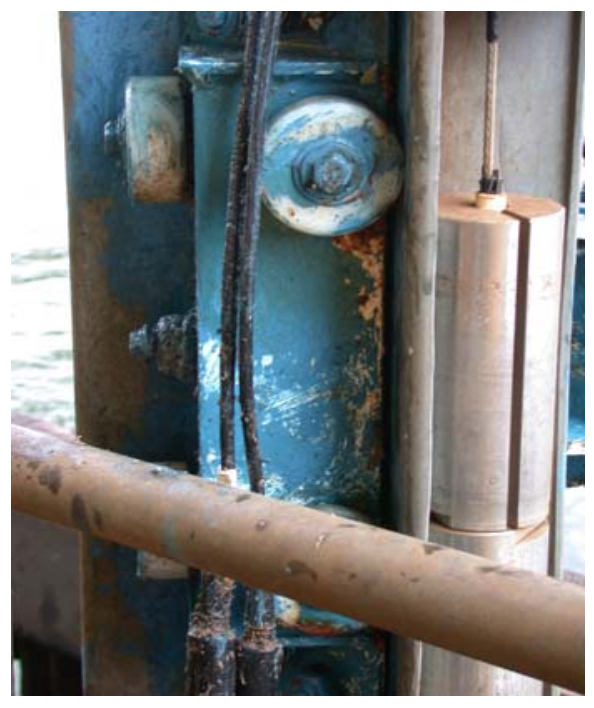

Fig. 6 Transducer carriage and support structure

identify the appropriate signal at each receiver. Fiveminute sequences are used to compute the average current for the period at each level. The water level sensor produces one-minute average readings, five of which are then averaged together to generate the value for the period. 

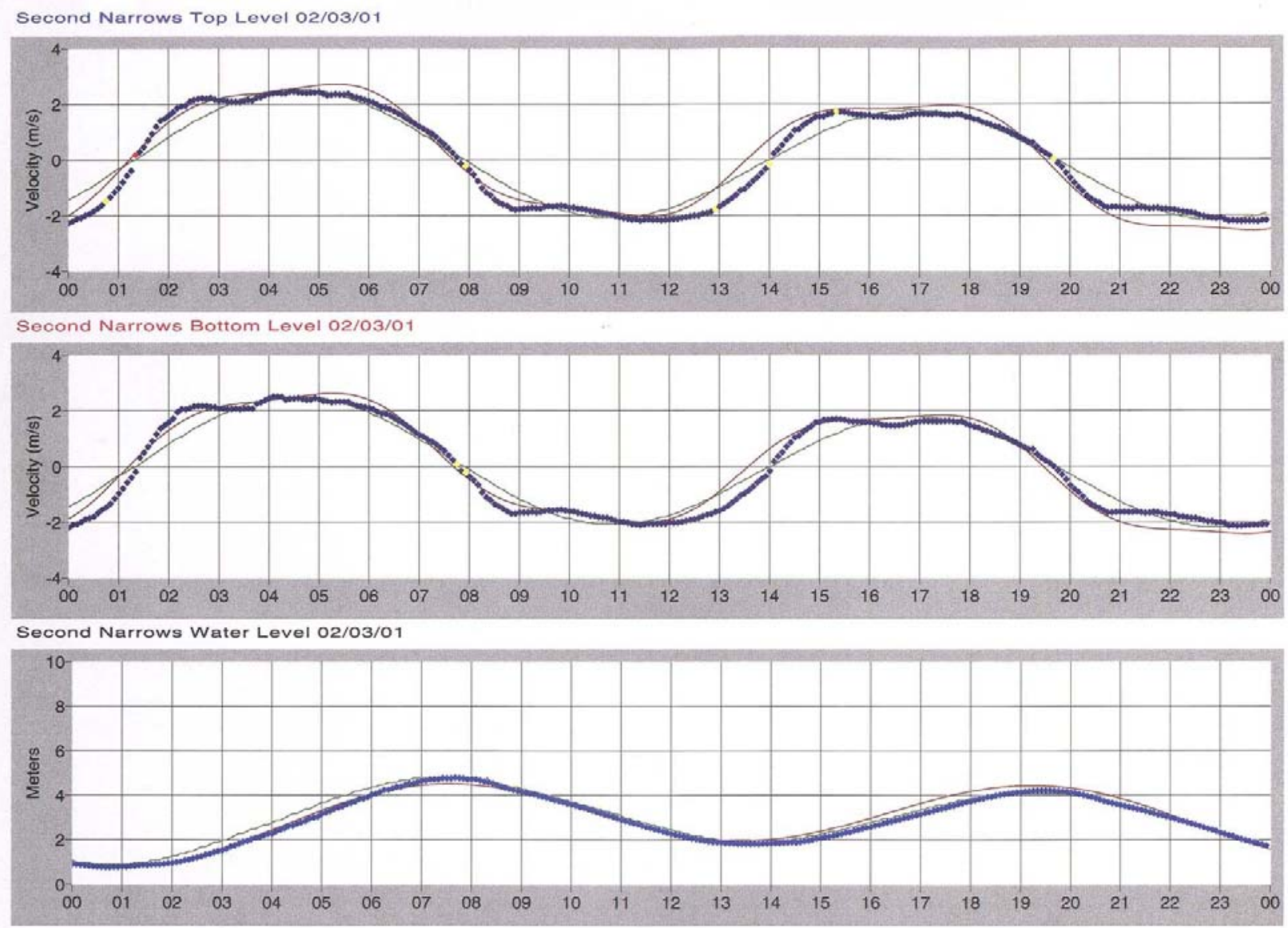

Fig. 7 Sample 24-hour data sequence.

Each current value is assigned a reliability index, calculated from the correlation coefficient of the pairs of acoustic time series. Index values lie between 0 and 10; values greater than 7 are labelled as reliable, those between 4 and 7 as to be used with caution, and those below 4 as unreliable.

The system output consists of the measured values of current and water level, the predicted values of the same quantities from the CHS tables, and a short-term (12 hour) forecast generated by fitting the two principal diurnal and semi-diurnal tidal constituents to the preceding 48 hours of data. Fig. 7 shows an example of one day's data. The measured data are shown as symbols, colour-coded by blue for reliable, yellow for caution and red for unreliable. Predictions from the CHS tables are shown as green lines, and the forecast by red lines. Note the distortion in the currents, relative to the predicted flows.

\section{B. Maintenance and Operation History}

The system was installed and became operational in March 2001. It operated continuously until June 2001 when a major power interruption at the bridge damaged the power supply to the receiver. A more robust UPS was installed which enabled the system to survive a similar power outage in May 2002 without damage or interruption of the measurements.

Fouling by marine growth was recognized during the design of the support structures as a significant issue. Antifouling paint was applied to the transducers, and the rail and trolley system was designed to allow servicing from the surface, by raising the arrays for cleaning. The trolleys were designed to ride over encrustations up to $2 \mathrm{~cm}$ in height. A site inspection after 8 months found greater fouling than had been anticipated on the upper levels. Fig. 8 shows an example of the growth on one of the trolleys. 


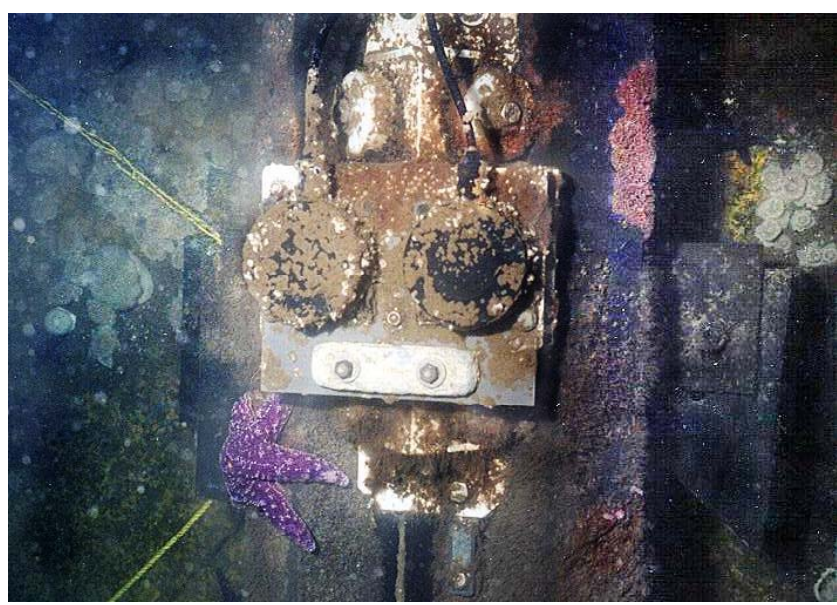

Fig. 8 Accumulation of marine growth on transducer carriage after 8 months deployment

The acoustic operation was unimpaired, but divers were required to clean the track so that the trolleys could be moved.

In May 2002, progressive degradation of the signal quality on the lower level became apparent, until it ceased operating on May 26. Investigation eventually revealed the cause to have been abrasion of the jacket of one of the transducer cables, which introduced a ground loop and elevated noise levels. The strong flows had caused a slack section of the cable to rub against the structure, eventually wearing through the jacket to expose the metal shield beneath. Replacing the damaged cable restored the system to full operation. The cable attachments were improved to prevent the problem recurring.

These two failures have been the only major interruptions in the system operation in the 2 years it has been in place. There have been other, short interruptions in the data flow, in most cases due to interruptions in the communication link. A hardware watchdog timer is included to ensure recovery in the event of crashes by the control computer. If the computer does not reset the watchdog within a specified time period, it reboots the system.

\section{Real-Time Data Display}

The time series of current at each level and water level are stored into binary files on the system hard disk. The optical fibre and wireless link between the Port Authority office and the bridge functions as an Ethernet network. Display software at the Port Authority office automatically accesses the current data file at the bridge; if it has been updated since the last time it was accessed, the file is copied and the output display updated. Fig. 10 shows a schematic of the data path between the instrument and the end-user display.
The end-user display is formatted as a web page, accessible over the Internet. At present, access is restricted to the project sponsors and users authorized by them. A sample of the display is shown in Figs. 11 - 13. The first view shows the most recent measured values are listed, along with the calculated values for draft and clearance under the bridge. The other two figures display a time history of the past 20 hours' measurements, and forecast and predicted values for the next 12 hours. Transit windows (i.e. those times during which the currents and water levels will be within allowable limits for large vessel passage) are shown superimposed as coloured rectangles (in corresponding colours) on the forecast and predicted current and water level curves. As may be seen in the example, the actual currents in particular may differ significantly from the predicted values and, as a result, the forecast transit windows can differ significantly as well.

\section{FUTURE OPERATIONAL USE}

The Second Narrows Current and Water Level Monitoring System was formally turned over to the Vancouver Port Authority in February 2003. The Port is continuing to maintain the flow of information to the display, and is evaluating means to integrate it with the routine scheduling of ship movements in the Port. Options are also being considered to incorporate the information from the Second Narrows system into an expanded Automated Identification System (AIS) or Universal Information System (UIS) network on the Canadian Pacific coast.

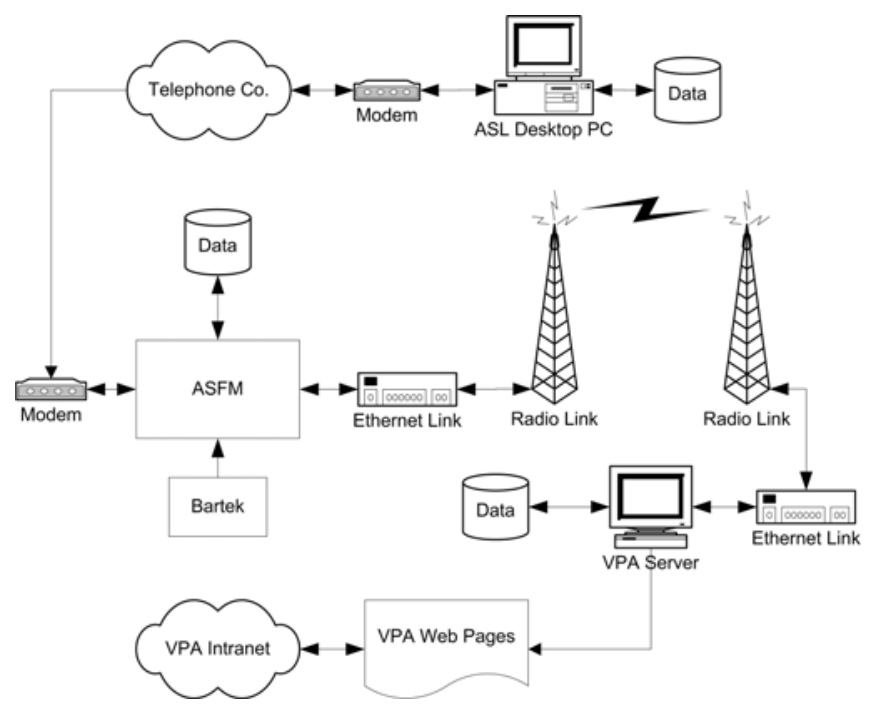

Fig. 10 Path for real-time data relay 


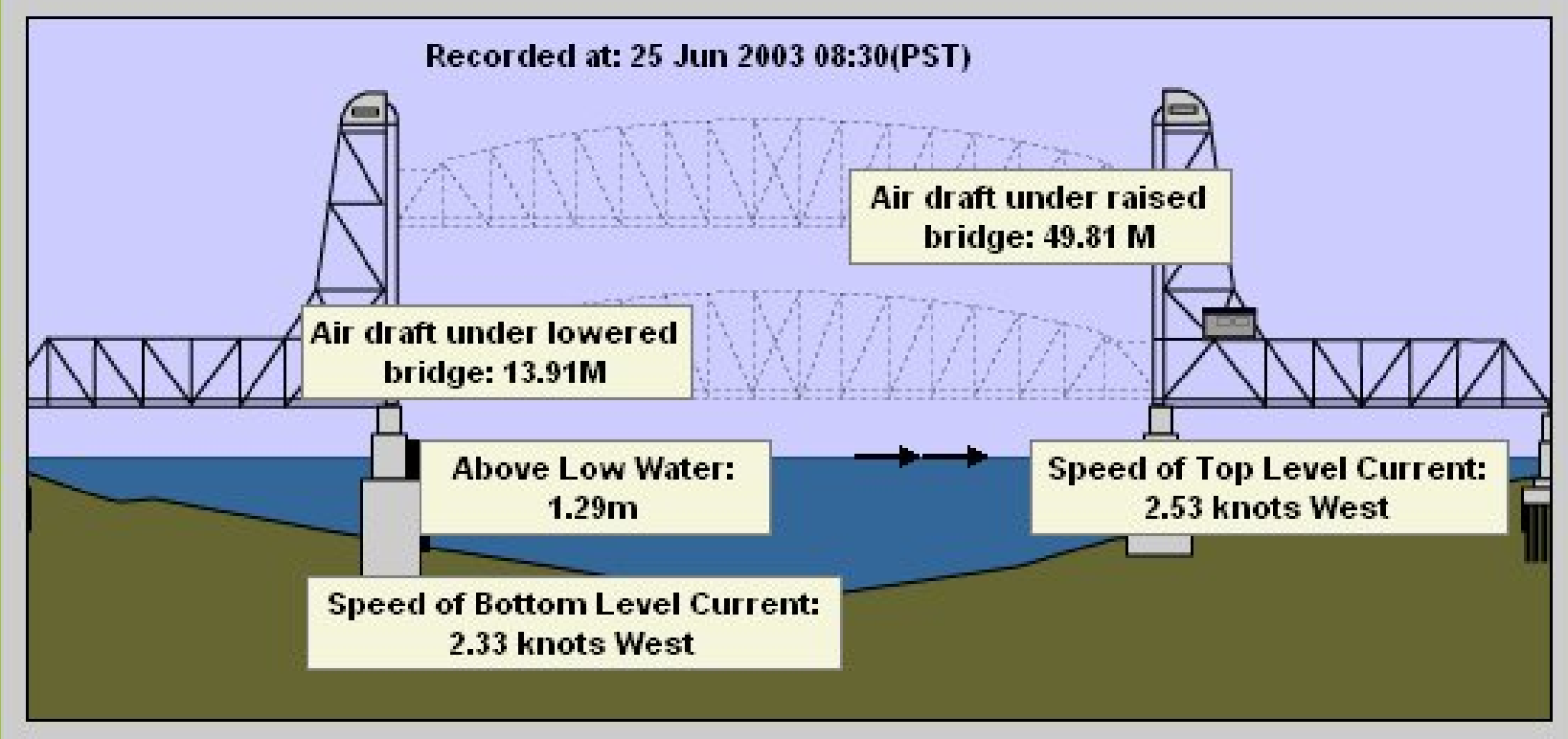

Fig. 11 Website display of most recent measured values and calculated drafts

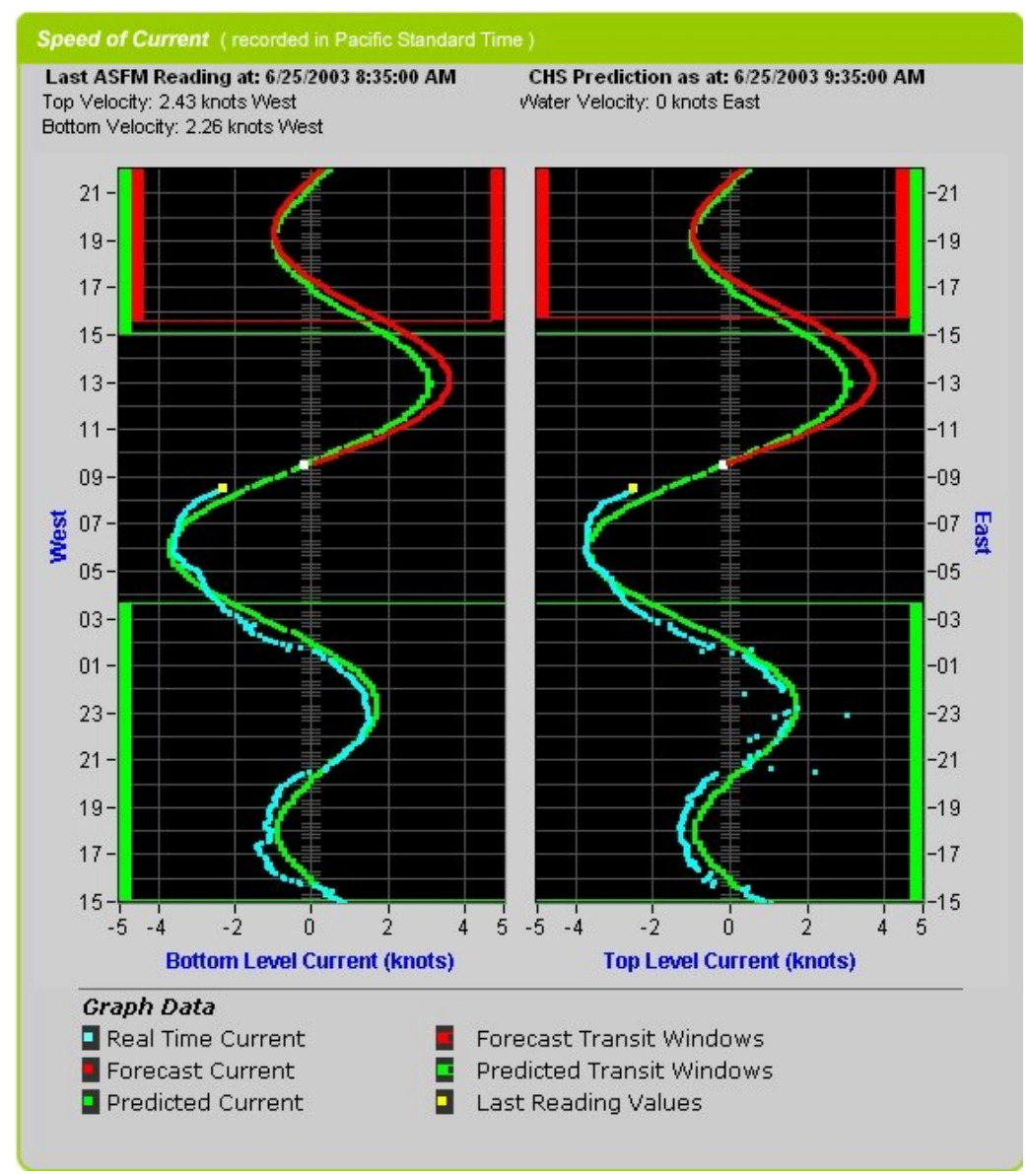

Fig. 12 Website display of current history and transit windows from predictions and forecast 


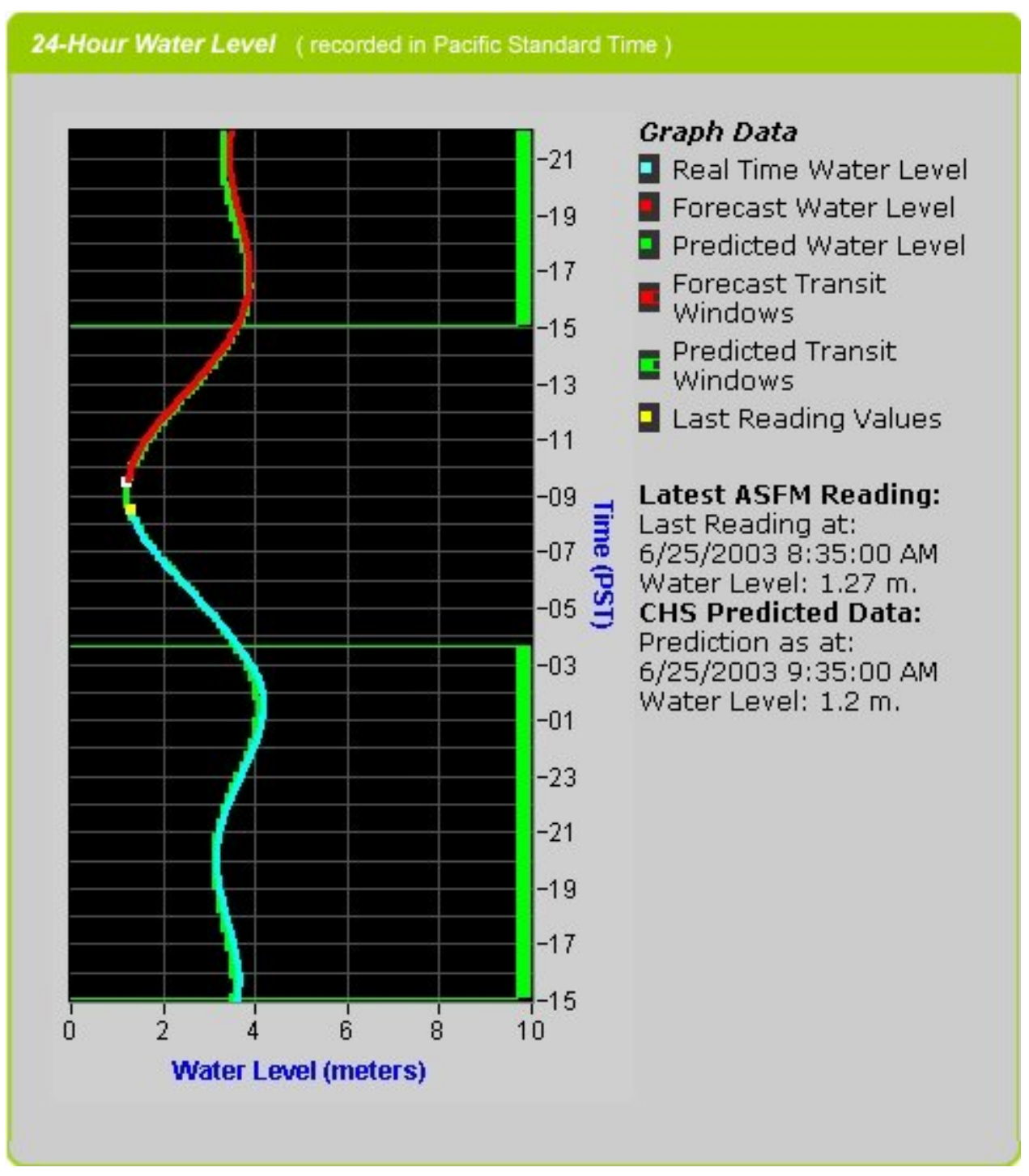

Fig. 13 Website display of water level history and transit windows from predictions and forecast

\section{Acknowledgments}

Financial support for the project came from the Government of Canada Programme for Energy Research and Development, CN Railway, Sultran Ltd. and the Vancouver Port Authority. Staff from CHS, ASL Environmental Sciences, VPA, CN Railway, FraserBurrard Diving and Fairview Wireless Ltd. all made vital contributions to the project's success.

\section{REFERENCES}

[1] S. F. Clifford and D. M. Farmer, "Ocean flow measurements using acoustic scintillation,” J. Acoust. Soc. Amer., vol.74 (6), pp. 1826-1832, December, 1983.
[2] D. M. Farmer and S. F. Clifford, "Space-time acoustic scintillation analysis: a new technique for probing ocean flows," IEEE J. Ocean. Eng., vol.OE-11 (1), January, 1986.

[3] D. M. Farmer, S. F. Clifford and J. A. Verrall, "Scintillation structure of a turbulent tidal flow," $J$. Geophys. Res., vol. 92 (C5), pp. 5396-5382, May, 1987.

[4] D. D. Lemon and D. M. Farmer, "Experience with a multi-depth scintillation flowmeter in the Fraser estuary," Proc. of the IEEE Fourth Working Conference on Current Measurement, Clinton, MD, pp. 290-298, April, 1990. 